\title{
Using multimedia and peer assessment to promote collaborative e-learning
}

\author{
ENRIQUE BARRA, SANDRA AGUIRRE HERRERA', \\ JOSE YGNACIO PASTOR CAÑO and JUAN QUEMADA VIVES
}

\begin{abstract}
Collaborative e-learning is increasingly appealing as a pedagogical approach that can positively affect student learning. We propose a didactical model that integrates multimedia with collaborative tools and peer assessment to foster collaborative e-learning. In this paper, we explain it and present the results of its application to the "International Seminars on Materials Science" online course. The proposed didactical model consists of five educational activities. In the first three, students review the multimedia resources proposed by the teacher in collaboration with their classmates. Then, in the last two activities, they create their own multimedia resources and assess those created by their classmates. These activities foster communication and collaboration among students and their ability to use and create multimedia resources. Our purpose is to encourage the creativity, motivation, and dynamism of the learning process for both teachers and students.
\end{abstract}

Keywords: Multimedia resources; Collaborative e-learning; Web 2.0; Didactical model; Assessment; Screencast

\section{Introduction}

These days students are commonly used to using social networks (Cheung et al. 2011) such as Facebook or Twitter and to deal with multimedia resources (Teoh and Neo 2006, Srivastava 2012), either by consuming them (like YouTube or Flickr) or by producing them (e.g. recording videos with their smartphones). These facts can be used to enhance student motivation and participation with the introduction of new educational activities into the learning process.

Collaborative e-learning is increasingly appealing to students and educational institutions as a learning approach (Lambropoulos et al. 2012). This responds to emerging trends in the field, which tend to integrate old paradigms of traditional learning with new paradigms based on collaborative social Web 2.0 (Torrisi 2010). 
On the other hand, Technology Enhanced Learning is currently fostering the creation of new multimedia educational resources and improving the way teachers transfer knowledge to their students. New technologies appear every day, but in many cases both teachers and students are not making the most of all the possibilities that these new technologies offer and how they can improve the way they teach, learn, and evaluate.

Almost every learning center or institution has a Learning Management System (LMS) (e.g. Moodle or Blackboard). These LMSs allow teachers to introduce different activities from simple to very complex ones and to use multimedia and collaborative methods in the learning process.

To take advantage of all these facts and introduce them into the learning process, the Comunica-Media project (http://innovacioneducativa.upm.es/cyber aula/inicio) was proposed and approved by the Technical University of Madrid (Universidad Politécnica de Madrid [UPM]). The main goal was to design and validate an innovative didactical model using these new technologies and the possibilities that existing LMSs offer. The main purpose of this didactical model should be to foster collaborative learning based on multimedia resources and multimedia production by the teacher and the students.

This paper will describe the designed didactical model and its validation in two different scenarios with the same online course. The main results are also presented and the most important challenges set out.

The rest of the paper is organized as follows. The next section reviews related work in the area of collaborative e-learning, multimedia, and peer assessment. Section 3 presents the Comunica-Media project, its requirements, challenges, and the initial hypothesis formulated. Section 4 presents the designed didactical model. Section 5 explains the two scenarios of the "International Seminars on Materials Science" course, and section 6 presents the results obtained. Finally, we discuss the improvements that this didactical model entails and the main difficulties and drawbacks that appear together with the conclusions and future work.

\section{Background}

Collaborative learning is a situation in which two or more people learn or attempt to learn something together (Dillenbourg 1999). It is based on the social learning theory and its evolution, the social cognitive theory by Canadian psychologist Albert Bandura (1976). Social learning theory was first published in 1941 by Miller and Dollard (1941). They proposed that if one was motivated to learn, they would observe a desired behavior and then imitate that action after clear observation, and upon solidifying the aped behavior, they would be rewarded with positive reinforcement, it thus becoming a learned behavior (Pichee 2012).

Many improvements and enhancements have been made in the field of collaborative learning (Goodsell 1994, Barkley et al. 2004). With the introduction of technology, collaborative learning becomes collaborative e-learning, also known as computer-supported collaborative learning (CSCL). It is a pedagogical approach wherein people learn together via social interaction using a computer. This kind of learning is characterized by the sharing and construction of 
knowledge among participants using technology as their primary means of communication or as a common resource (Koschmann 1996).

As technology evolves, CSCL incorporates these innovations and evolves, making it very different today than it was back in the 1990s (Stahl et al. 2006).

Web 2.0 technologies offer a great potential for the future of technologyenhanced learning (Ullrich et al. 2008). The key Web 2.0 services include blogs, wikis, multimedia sharing services, content syndication, podcasting, and content tagging services (Anderson 2007). Most LMSs such as Blackboard and Moodle have integrated these services, which allow both teacher and students to create and share content and to stimulate active participation (Zdravkova et al. 2011, Harris and Rausch 2013).

In addition, with the advancement in digital technology in transmission and multimedia content, education has become semantically richer. Interactive multimedia content has the capability of improving learning performance by enhancing user satisfaction and engagement (Cheng et al. 2010). The introduction of multimedia into education allows teachers to improve their teaching and assessment styles through a set of tools that combine text, graphics, audio, and video. Examples include lecture recording tools, videoconferencing tools, and podcast tools. Multimedia tools and software applications are widely used in education (Ferretti et al. 2008, Bolliger et al. 2010, Lawson et al. 2010). They are helpful for cooperative learning, critical thinking, discussions, problem solving, and selfstudy (Jiao and Chen 2011). These powerful tools may help transform the present classrooms into rich, student-focused, and interactive knowledge environments (Mahajan 2012).

The need for multimedia instructional material in e-learning has recently experienced a considerable increase as this content has been shown to attract the student's attention and interests (Sun and Cheng 2007). In recent years, several Web-based sharing and community services such as Flickr and YouTube have made a vast and rapidly growing amount of multimedia content available online (Naaman 2012). Students can use multimedia to create projects, design portfolios, and complete assignments. The production of multimedia resources by the student is a way of promoting student involvement in the learning process. Working on multimedia production addresses the need for students to increase their ability to create and communicate, improving their media literacy skills as well as fostering their capabilities with computing technologies (Green and Brown 2002).

According to Krippel et al. (2010), the use of multimedia will be more effective for abstract conceptual and theoretical content material than quantitative areas where the material requires extensive problem solving. However, the efficacy of multimedia instruction will depend on the teaching skills, motivation, social trends, and technology skills of the students.

In the recent years, there has been an increase in the use of peer assessment in higher education learning environments (Segers et al. 2003). A peer assessment can be described as a process whereby students evaluate, or are evaluated by, their peers. A wide variety of activities can be peer assessed such as writing, oral presentations, and portfolios. According to Falchikov (2005), involving students 
in the assessment of presentations is extremely beneficial for developing self-regulated skills. The reliability and validity of peer assessments tend to be at least as high, and often higher, than teacher assessments (Topping 1998).

\section{Research design}

UPM online learning process usually followed a passive approach where teachers deliver educational content and students review them and finalize the process with an online or in-person exam. This is a big concern at the UPM and so it is expressed in the Educational Innovation Program main objectives. Objective 1 of this program is to "Improve the efficiency of the learning process with special attention to the incorporation of active learning methodologies," and objective 2 is to "improve the evaluation and grading systems" (UPM Educational Innovation Program 2013).

To address this problem the Comunica-Media project was proposed and approved. The Comunica-Media project is also known as "CyberAula 2.0" as it is the continuation of the previous project called CyberAula (Aguirre Herrera et al. 2011, Barra et al. 2011). Both projects are part of the UPM Educational Innovation Program.

In the former project, some in-person courses were recorded to produce multimedia content that could be used in the future together with videoconferencing experiences. These multimedia resources and the knowledge acquired in the CyberAula project were used as input in the Comunica-Media project.

The main goal of the Comunica-Media project was to design a new didactical model to foster collaborative learning based on multimedia resources and multimedia production by the teacher and the students. This goal would then rely on three pillars:

- Collaborative learning: interactions, communications, and finally collaboration between teacher-student and among students.

- Teachers' and students' abilities to produce multimedia content: not only the teacher creates multimedia resources, students should also be able to do so.

- Peer assessment of the multimedia resources created: students will learn from the resources created by their classmates as well as assessing them. The final grade should consider this assessment.

With all this in mind the main hypothesis proposed for this research was:

The introduction of students' production of the multimedia resources together with its peer assessment would encourage them to actively participate in the collaborative learning process.

\section{Designed didactical model}

The classic e-learning process usually consists of the creation (or re-use) of educational resources (e.g. a presentation or texts notes) by the teachers and their use by students (Sbihi and El Kadiri 2010). Likewise, the assessment process follows the same behavior in which the teachers provide the educational resources 


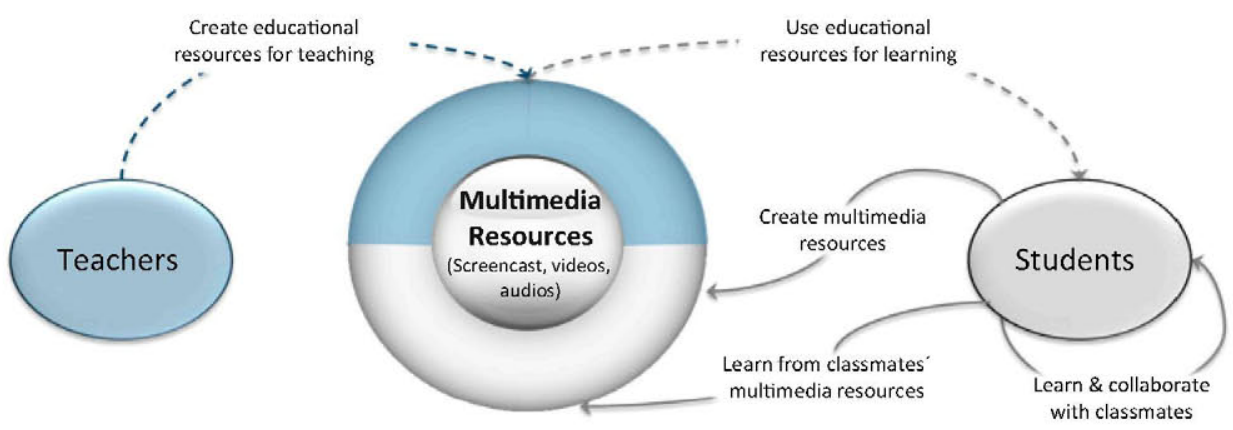

Figure 1. Teaching and learning process.

and the students use them (Herrington et al. 2009). These processes are represented by the dotted lines in Figures 1 and 2.

In order to enhance the teaching, learning, and assessment processes together with the students' participation in them, we propose the use of multimedia resources and the creation of new educational activities in both processes.

The teaching and learning process includes all the interactions between teachers and students or between them with the purpose of transmitting knowledge and information, for it to be learned. This process is not unidirectional and students can participate. However, this participation is harder in online environments, as the students do not know each other and the communication is made in an asynchronous way. Some activities can be introduced into this process to foster student participation. These activities are represented by solid lines in Figure 1, and are as follows:

- Students can create multimedia resources as homework. With this activity, the student acquires key skills such as communications and computer skills and content organization. Students have used multimedia resources during the regular activities of the course or in other courses and now they have to produce them.

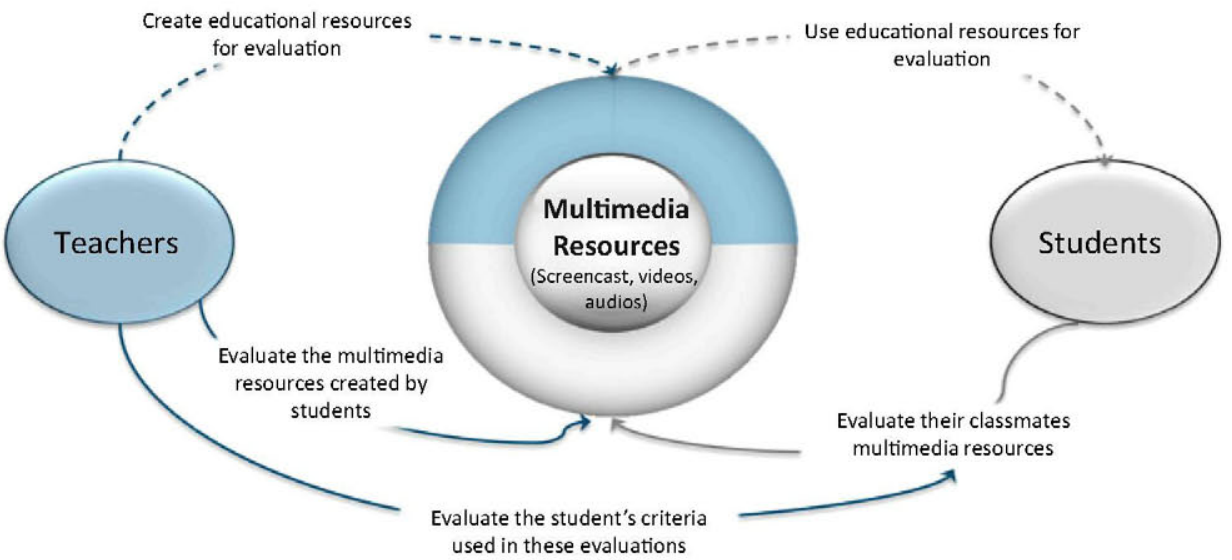

Figure 2. Assessment process. 
- Students can learn and collaborate with their classmates and the teacher through a collaboration tool (forum, blog, wiki, etc.), where they share and discuss ideas and get and give help to create their multimedia resources.

- Finally, students can learn from their classmates by reviewing the multimedia resources that they have created.

As regards the assessment process, the teacher traditionally evaluates the skills, knowledge, or abilities acquired as a result of the teaching and learning process, thus generating a final grade. In this didactical model both teacher and students enhance this process through the development of new educational activities and the use of multimedia resources. The new educational activities proposed and represented by solid lines in Figure 2 are:

Teacher:

- Evaluate student's work on a specific topic with the multimedia resources created.

- Evaluate the peer assessments. The purpose is to assess the application of marking criteria and whether the multimedia resources were really reviewed by students or not.

Students:

- Peer assessment of the multimedia resources produced by their classmates. This activity allows them to develop their evaluation criteria and obliges them to review their classmates' multimedia resources.

For simplicity, hereinafter we shall call the whole educational process involving teaching, learning, and assessment processes, the learning process.

\subsection{Activities}

The application of the didactical model explained in an online course gives rise to five activities. These activities are listed in Table 1 and will be detailed in the

Table 1. Activities.

\begin{tabular}{|c|c|c|c|c|}
\hline Activity & Objective & $\begin{array}{l}\text { Carried } \\
\text { out by }\end{array}$ & Platform/program & Schedule \\
\hline $\begin{array}{l}\text { Multimedia resource } \\
\text { review }\end{array}$ & Learning & Students & $\begin{array}{l}\text { Depends on the } \\
\text { multimedia resource to use }\end{array}$ & Weekly \\
\hline Questionnaire & Assessment & Students & LMS & Weekly \\
\hline Collaboration tool & $\begin{array}{l}\text { Learning, } \\
\text { assessment }\end{array}$ & $\begin{array}{l}\text { Students, } \\
\text { teacher }\end{array}$ & LMS & Weekly \\
\hline $\begin{array}{l}\text { Multimedia resource } \\
\text { creation }\end{array}$ & $\begin{array}{l}\text { Learning, } \\
\text { assessment }\end{array}$ & Students & $\begin{array}{l}\text { Multimedia resource } \\
\text { creation tool and LMS }\end{array}$ & $\begin{array}{l}\text { Penultimate } \\
\text { fortnight }\end{array}$ \\
\hline $\begin{array}{l}\text { Classmates' multimedia } \\
\text { resources evaluation }\end{array}$ & $\begin{array}{l}\text { Learning, } \\
\text { assessment }\end{array}$ & $\begin{array}{l}\text { Students, } \\
\text { teacher }\end{array}$ & LMS & $\begin{array}{l}\text { Last } \\
\text { fortnight }\end{array}$ \\
\hline
\end{tabular}


following subsections. These activities are described here generically and all of them should be done in the same LMS. These descriptions are intended to be a guideline for teachers/tutors to apply this didactical model in their own course and LMS. In the results section we will explain how we have applied them to our course using Moodle.

4.1.1. First activity: multimedia resource reviewing. This activity covers the whole period of the course. Availability, content quality, and suitability are the criteria used for the choice of resource. A video lecture is the most common option. However, in some scenarios a podcast or an audio class along with a presentation is enough.

The multimedia resource reviewing activity is done weekly, so the students do not lag behind, that is, students have to review one resource of about one hour duration every week. Considering that these multimedia resources are available online, students can review them when they want and as many times as they want during the week. The main purpose of this activity is for the students to learn about the content and topics explained in the multimedia resources.

4.1.2. Second activity: questionnaire. The second activity is closely related to the first one and consists of a questionnaire on the multimedia resource that the students have to fill out in the same week or the following one.

This questionnaire should consist of at least five multiple-choice questions randomly chosen by the LMS from among a pool of questions. It should be done this way to avoid students copying one another. The maximum duration of each questionnaire should be under 30 minutes to avoid students getting the answers from Internet without reviewing the multimedia resources.

The objective of this activity is to assess students and to check whether they have reviewed and assimilated the multimedia resources of the first activity.

4.1.3. Third activity: collaboration tool. This activity can be carried out with any collaboration tool that the LMS provides, such as a blog, a forum, or a wiki.

At the beginning of each week the teacher creates a forum, a blog post, or a wiki entry in the LMS and asks the students to participate in it. The first comment added by the teacher could be just the title of the multimedia resource, its summary, or an open question related to it. After this first entry the teacher can decide if he/she wants to actively participate in the collaboration tool or just be a spectator.

The aim of this activity is to get the students to give their opinion of every resource, collaborate among themselves, meet each other, and propose new ideas and comments.

The teacher will be able to assess their contributions. Using these contributions for grading the students is one of the best methods to increase students' participation in asynchronous discussions (Dennen 2005). In some cases the teacher will only use the number of contributions but in other cases the teacher can assess the quality of the content. This will depend on the balance in the use of quantitative and qualitative assessment that the teacher wants to have (Kendle and 
Northcote 2000) and in if he/she has help from other teachers for this task. Furthermore, with this activity teachers can improve the teaching process, solve errors and misunderstandings as well as identify topics of interest through student feedback and comments.

4.1.4. Fourth activity: multimedia resource creation. During the penultimate fortnight of the course the students have to create their own multimedia resources. They should be between 10 and 15 minutes in duration. The multimedia resource can be a screencast or a presentation with attached audio explanations. A screencast is a recording of the computer screen output, also known as a video-screen capture, often containing audio narration. It can also integrate video from the user webcam. Screencast can be also post-produced to remove unwanted parts. It will depend on the student's ability to manage screencast tools. As the students usually have no previous experience creating multimedia resources, a step by step manual should be prepared and provided to them.

At the same time, the students also get the rubric that will be used to assess them. Thus, they can consider the factors that will be used when assessing their work.

The presentation topic can be anything related to the course, a theoretical study, historical or economics facts, an experiment, etc.

This activity allows the students to learn about the topic chosen as well as to acquire and improve their key transversal skills:

- Computer skills when they create their own multimedia resource

- Documentation, applying and synthesizing knowledge when they prepare, and organizing the presentation

- Communication skills when they give the presentation

4.1.5. Fifth activity: classmate multimedia resource evaluation. Finally, a fortnight before the end of the period the students have to review some multimedia resources created by their classmates. Between 10 and 12 resources are assigned to each student. They will also have to fill out the rubric for assessment. This assessment can be used to grade them and as a side-effect to check that they have reviewed the resources.

Through this activity the students will learn from their classmates' presentations. But again they will acquire a very important key transversal skills, critical thinking, and evaluation criteria.

\section{Scenario}

The designed didactical model has been applied to the course called "International Seminars on Materials Science". It is a fully online course offered by the Department of Materials Science of the UPM in both semesters in different scenarios. The duration of this course is 15 weeks in both cases. This course is based on the development of seminars that disseminate current and outstanding issues within the area of Materials Science and Engineering. These issues vary from biological materials and functional materials to purely technological applications. With this course students are expected not only to learn about 
novelties in the field of Materials Science but also to develop key transversal skills due to the application of this didactical model.

The scenario for the first semester has been carried out in the context of the ADA-Madrid project (acronym for Online University Classroom in Madrid). This project started in 2001 and involves the six public universities in Madrid. Last year ADA-Madrid offered 44 courses and had 2,610 students (Universidad Politécnica de Madrid 2010). In accordance with the project policies, a maximum of 10 students from each university can be enrolled in the same course, thus multidisciplinary collaboration among students is fostered.

Students from the six public universities in Madrid were enrolled in our course. They came from different undergraduate studies (from economics, law, and linguistics to chemistry, physics, and engineering). So, in this first scenario we had a sample of multidisciplinary students. In the first semester, 40 students started the course, but three of them dropped-out in the second week and the remaining 37 students completed the course.

In the second semester, the same course called "International Seminars on Materials Science" has been given. In this case it was offered under the elective courses program of UPM. Students from any UPM degree course could enroll. So, in this case, we had more technical students but also multidisciplinary ones. For this scenario we had 22 students who started the course although two of them dropped-out in the beginning and 20 completed it.

In both scenarios, the students had no previous experience in the field of Materials Science or in the creation of multimedia resources.

\section{Results}

In this section we will present the activities resulting from applying the didactical model presented to the course and the data collected in each one of them. All the activities explained in this section have been carried out with Moodle as it is the LMS used in both ADA-Madrid project and the UPM elective courses program.

The data collected have been gathered from the Moodle reports. These reports only include objective data such as the number of views or posts. They have been used to evaluate the success of each activity as well as grading the students. The final grade was calculated by considering the individual grades obtained in every activity. Sixty-two percent of the grade was based on the questionnaires, $15 \%$ on collaboration in the forum, and $23 \%$ on the multimedia resource created and the student's evaluations of their classmates' multimedia resource.

The data presented are the sum of the students in both scenarios, a total of 62 students who started the course and the 57 who completed it. We have put the results together because they were very close in both scenarios.

After the course finished, a survey was conducted between the students to measure the acceptance of this didactical model. Survey results are subjective data as they present students' opinions about many topics. These results will be also presented at the end of this section and will be compared with the average results of the same survey conducted between the students of the other 44 courses of the ADA-Madrid project. 


\subsection{Multimedia resource reviewing: seminar recordings}

The multimedia resources that we used for this activity were seminar recordings obtained as the result of the previous project called CyberAula where all the seminars in the face-to-face "Materials Science" course were recorded (Pastor and Atienza 2011). In these seminars, an international or a national expert in a field of material science gave a master class about a research or advanced topic. Sometimes these topics were not even in the books as they presented recent discoveries and research studies in their fields.

These videos were on the UPM Channel on Youtube and the UPM audiovisual platform. They were duplicated so the students could use the one they preferred and felt more comfortable with. They were linked as external resources in the Moodle course content (organized in weeks). The main aim of this activity was for students to learn about the seminars that the teacher had selected from among those recorded in CyberAula. An example of one of these recordings can be seen in Figure 3, and the results of this activity are summarized in Table 2.

In the first two weeks the number of viewings was higher because students do not know how the course worked. The total viewings in weeks 9 and 10 were lower because it coincided with the Christmas holiday period in the first semester.

On average every video was accessed at least twice by the student to review it and answer the questionnaire properly.

\subsection{Questionnaire: weekly questionnaire}

This questionnaire was a Moodle activity and consisted of five multiple-choice questions that were randomly chosen by the program from among a pool of about 20 questions. Students had from Thursday to Sunday to answer a questionnaire on the recording in order to prove their comprehension.

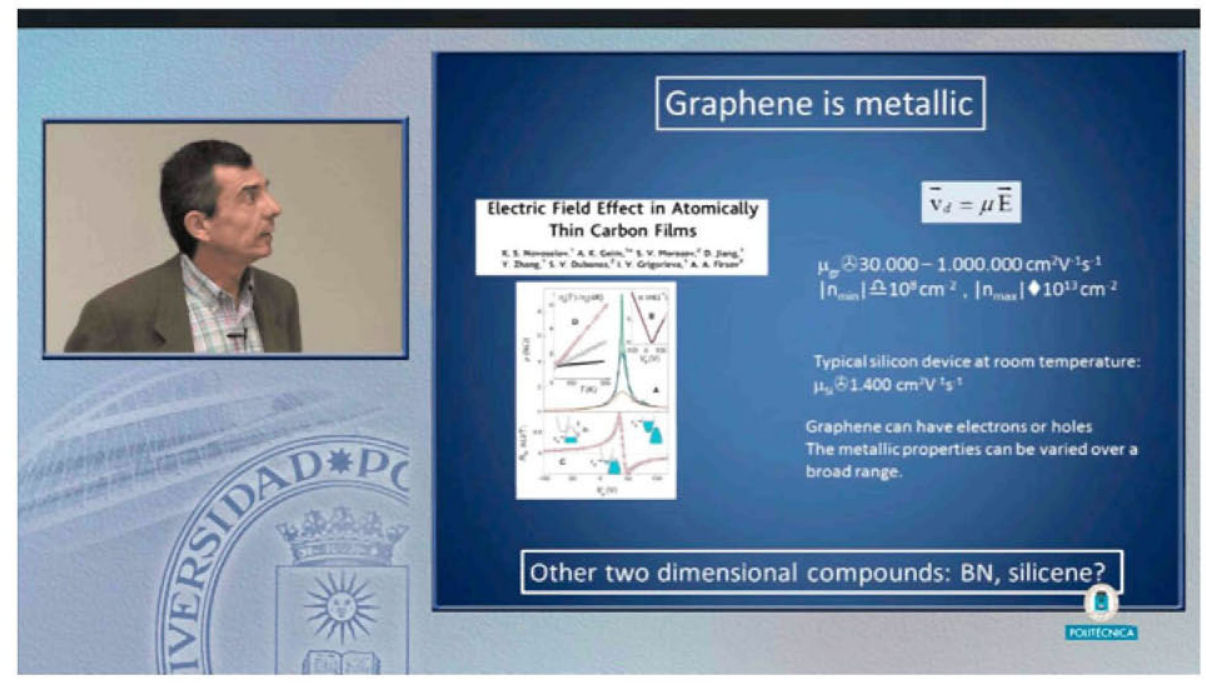

Figure 3. A printed screen of an international seminar on materials using YouTube. 
Table 2. First activity results.

\begin{tabular}{lc}
\hline Week & Total views \\
\hline 1 & 345 \\
2 & 184 \\
3 & 138 \\
4 & 137 \\
5 & 146 \\
6 & 128 \\
7 & 100 \\
8 & 102 \\
9 & 89 \\
10 & 78 \\
11 & 94 \\
12 & 121 \\
13 & 113 \\
\hline
\end{tabular}

As in the first activity the content of these questionnaires (the questions themselves) was re-used. These questions were generated by the students from the face-to-face "Materials Science" course. They had to write two multiple-choice questions after each seminar to prove that they had paid attention.

We can see in Table 3 that the average grade varied from 6.53 to 8.86 . This is because some topics were more advanced than others and so harder to understand. The standard deviation was between 1.47 and 2.68, indicating that the grades were quite near the average value. Finally, the average grade was above 7 except for the first week, indicating that the students had reviewed the videos of the first activity and that they answered correctly most of the questions.

\subsection{Collaboration tool: forum}

As a collaboration tool we chose a forum. Each week the teacher created a forum activity in Moodle with the title of the recorded seminar. The students were those

Table 3. Second activity results.

\begin{tabular}{lcc}
\hline Week & Average grade & Standard deviation \\
\hline 1 & 6.53 & 1.97 \\
2 & 7.33 & 2.38 \\
3 & 8.58 & 1.81 \\
4 & 7.11 & 2.08 \\
5 & 7.00 & 2.68 \\
6 & 7.92 & 1.90 \\
7 & 8.66 & 1.66 \\
8 & 8.13 & 1.97 \\
9 & 7.51 & 2.41 \\
10 & 8.86 & 1.57 \\
11 & 8.09 & 1.57 \\
12 & 7.72 & 1.95 \\
13 & 8.79 & 1.47 \\
\hline
\end{tabular}


Table 4. Third activity results.

\begin{tabular}{lccc}
\hline Week & Forum threads & Number of posts & Number of views \\
\hline 1 & 7 & 46 & 597 \\
2 & 11 & 51 & 630 \\
3 & 9 & 50 & 592 \\
4 & 9 & 46 & 404 \\
5 & 10 & 67 & 545 \\
6 & 9 & 46 & 366 \\
7 & 5 & 56 & 332 \\
8 & 6 & 69 & 459 \\
9 & 12 & 88 & 669 \\
10 & 7 & 55 & 357 \\
11 & 7 & 70 & 494 \\
12 & 8 & 81 & 459 \\
13 & 10 & 91 & 515 \\
\hline
\end{tabular}

in charge of establishing the different forum threads, collaborating, giving their opinion, etc.

Table 4 shows that students participated a lot in the forums. These forums were where they looked for help from the teacher or their classmates, about topics that they did not understand and wanted to understand better before doing the questionnaire, and about technical issues with the LMS or doubts with their multimedia creation task.

\subsection{Multimedia resource creation: screencast and presentation with audio explanations}

The multimedia resource that the students had to create was either a screencast or a presentation with attached audio explanations. Each student had to produce a multimedia resource.

When choosing the screencast option, each student could also choose to record only his audio and presentation or to include his webcam recording to make it more interactive. As the students had no previous experience creating multimedia resources, a step by step manual was prepared and provided to them. Support from the teacher and a technician was also offered in case they encountered problems in the creation process.

In Table 5, we can see that 44 out of 57 students $(77.19 \%)$ chose the screencast over the presentation option. This was a surprise because they could freely choose any of the options, and the presentation with audio was easier to do as it only

Table 5. Fourth activity results.

\begin{tabular}{lcc}
\hline Type of resource & No & Grade for submission (average) \\
\hline Screencasts including webcam & 24 & 7.46 \\
Screencast without webcam & 20 & 7.09 \\
Presentation with audio & 13 & 5.88 \\
\hline
\end{tabular}




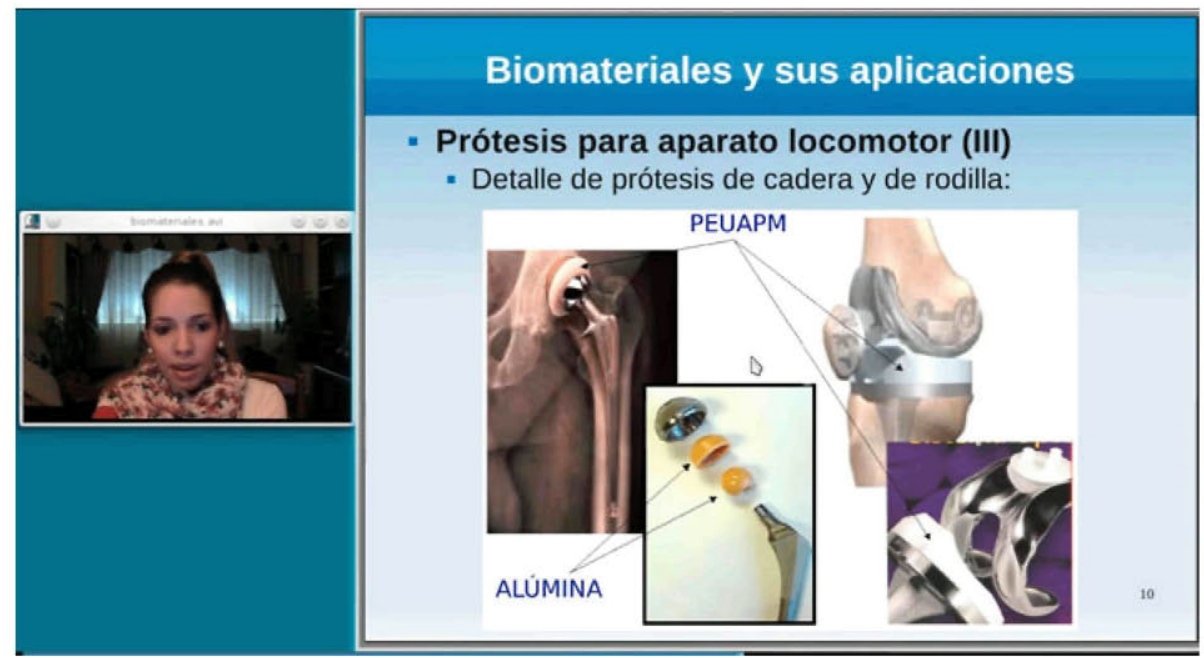

Figure 4. Screencast with webcam.

involved one program (PowerPoint or OpenOffice for example) and they were more used to it. Furthermore, when asked they said that they had decided to take the opportunity to learn something new that they found very interesting and useful.

When the students reviewed their classmates' resources, they graded the screencasts higher than the presentations (more than one point on average). Twenty-four out of 44 screencasts $(54.54 \%)$ included the webcam, and in this case their grade was slightly higher.

We can see two examples of these works in Figures 4 and 5.
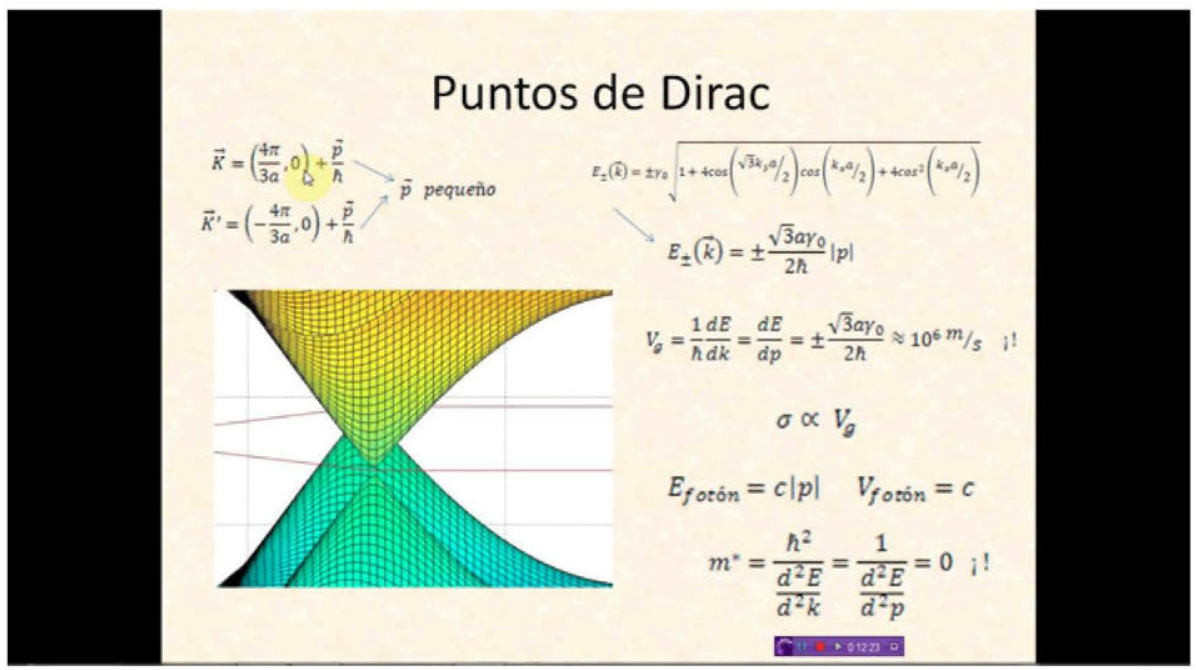

Figure 5. Screencast without webcam. 
Table 6. Fifth activity results.

Type resource used

Student that created screencasts including webcam (24)

Student that created screencast without webcam (20)

Student that created presentation with audio (13)

Average grade (57)

Standard deviation
Grade for assessment (average)

\subsection{Classmate multimedia resource evaluation: workshop}

For this last step we used the Moodle workshop activity. In this activity, Moodle randomly assigns each student with a number of resources from his/her classmates to be reviewed and evaluated. Moodle also automatically assigns a mark to the student's evaluation of each resource. This mark is between 0 and 20 . The nearer the student reviewer's mark to the average evaluation mark, the higher the mark given to the reviewer.

In this case, they had to review 12 resources and fill in the rubric to evaluate them. The final grade was the average of the 12 evaluations that the student made.

During the workshop activity, we used the following rubrics: content organization, communication skills, presentation design, technical resources used, creativity, quality of information, originality, knowledge of the topic, relevancy to the course, and documentation.

With this data we can assert that the students really reviewed the resources created by their classmates and that they filled in the rubric with dedication. Students who created the screencasts showed more interest in the course and carried out a better review of their classmates' resources, thus obtaining higher grades (Table 6).

\subsection{Teacher and students feedback}

After the course finished, a voluntary survey was conducted among the students. Thirty-eight of them completed the 5-point Likert (1932) scale questionnaire; they had to rate some statements between 1 (very bad) and 5 (very good). The results are summarized in Table 7 where the last two columns show the average results for this course and the average results for all the 44 courses of the ADA-Madrid project.

We can see in the survey results table that this course obtained better results than the average. Special attention should be given to the "number of activities" statement because we were afraid that there could be too many of them but students rated this higher than the average course. The "type of activities" was also rated higher, showing that they appreciate doing different things and developing their transversal skills. The only statement that is below average is the first one "dissemination of the project in my university", and the whole ADAMadrid project is working on this issue to try to improve it. 
Table 7. Survey results.

\begin{tabular}{lcccccccc}
\hline & $\begin{array}{c}1 \\
\text { Question }\end{array}$ & $\begin{array}{c}2 \\
(\%)\end{array}$ & $\begin{array}{c}3 \\
(\%)\end{array}$ & $\begin{array}{c}4 \\
(\%)\end{array}$ & $\begin{array}{c}5 \\
(\%)\end{array}$ & Average & $\begin{array}{c}\text { Average of } \\
\text { all courses }\end{array}$ \\
\hline $\begin{array}{l}\text { The dissemination of this project in my } \\
\text { university }\end{array}$ & 5.3 & 47.4 & 34.2 & 2.6 & 10.5 & 2.7 & 2.8 \\
$\begin{array}{l}\text { My motivation with this course } \\
\begin{array}{l}\text { The didactical model applied in the } \\
\text { course }\end{array}\end{array}$ & 0 & 5.3 & 10.5 & 42.1 & 42.1 & 4.2 & 3.9 \\
$\begin{array}{l}\text { Student implication in the learning } \\
\text { process }\end{array}$ & 0 & 0 & 15.8 & 50.0 & 34.2 & 4.2 & 3.9 \\
$\begin{array}{l}\text { The presentation (format, accessibility, } \\
\text { duration) of the educational content }\end{array}$ & 0 & 0 & 0 & 52.6 & 47.4 & 4.5 & 4 \\
$\begin{array}{l}\text { The number of activities scheduled } \\
\text { (forums, homework...) }\end{array}$ & 0 & 5.3 & 5.3 & 36.8 & 52.6 & 4.4 & 3.7 \\
$\begin{array}{l}\text { The type of activities used } \\
\begin{array}{l}\text { Degree to which the activities have } \\
\text { facilitated collaborative learning }\end{array}\end{array}$ & 0 & 0 & 0 & 21.1 & 44.7 & 34.2 & 4.1 & 3.7 \\
$\begin{array}{l}\text { The level of collaboration between } \\
\text { students encouraged by the teacher }\end{array}$ & 0 & 7.9 & 18.4 & 31.6 & 42.1 & 4.1 & 3.4 \\
$\begin{array}{l}\text { The level of interaction with the teacher } \\
\text { in the forums }\end{array}$ & 0 & 10.5 & 5.3 & 21.1 & 63.2 & 4.4 & 3.8 \\
$\begin{array}{l}\text { The level of interaction with other } \\
\text { students in the forums }\end{array}$ & 0 & 0 & 13.2 & 15.8 & 71.1 & 4.6 & 3.4 \\
\begin{tabular}{l} 
The assessment process \\
\hline
\end{tabular} & 0 & 0 & 5.3 & 50.0 & 44.7 & 4.4 & 4 \\
\hline
\end{tabular}

On the other side, an informal open interview with the teacher was conducted. This teacher is also a participant in the design of the didactical model and an author of this paper. He identified the generation of the questionnaires and the organization of the full course in Moodle as the most difficult parts as the interface was not very usable and it was a little slow. The teacher also stated that the easiest part was the correction of the questionnaires as it was automatic and the most positive part the interaction among students from different places, with different interests and education. Finally the teacher believes that this didactical model can be easily applied in other subjects as it is generic. He would recommend its application to other colleagues but warn about the extra effort that needs to be done.

\section{Discussion}

In this section we will discuss how the results presented can validate the initial hypothesis and we will analyze the strengths and weaknesses of this didactical model. Finally we will present the main problems that arose during the course and how we looked at them.

On the one hand we see in the activities results that students followed the course with interest and carried out all the activities. They reviewed the weekly videos and filled in the questionnaires, thus obtaining good grades. They collaborated in the forum, which was the meeting point and an activity connected 
to all the others, as it is the place where the students looked for help and helped their colleagues and where they expressed their opinions. Finally the students produced multimedia content and assessed the work done by others by filling in the rubric.

On the other hand, the survey results show that students were motivated and implicated in this didactical model. One concern that we found when designing this didactical model was on the number of activities that the students would have to do but in the survey results we can see that most of the students rated the number and type of activities as good or very good. Finally, in the students' opinion one of the areas to be improved is the dissemination of the project.

The main problem to validate these results is the lack of significance of the objective data. We don't have a control group with the same course and without this didactical model to compare with. Nevertheless, the survey results can be compared with the average of the rest of the courses. So with the objective data we can confirm that the students followed the course with interest and that they did all the activities. With the survey results and its comparison with the average data we can prove that students liked this didactical model, they were motivated and involved in the learning process, and they also liked the activities.

With all these results we can assert that the initial hypothesis was validated. Also, the designed didactical model meets the project goals and objectives. The introduction of students' production of the multimedia resources together with its peer assessment encouraged them to actively participate in the collaborative learning process.

The main strengths of this didactical model are that it can be done with a very popular and widely used LMS such as Moodle and that it encourages students to collaborate and become implicated in their learning and to produce multimedia content themselves. But in contrast, this didactical model has some weaknesses. The first one is that the course teacher needs to dominate the use of the LMS to create and configure the activities as well as dominating the creation of multimedia resources to be able to help the students. Another significant weakness is, in some cases, having multimedia content available and appropriate that fits the course objectives and that can engage the students and motivate them to create their own multimedia resources.

The carrying out of any online course with new activities comes with some difficulties and problems that can arise. The first one that we encountered was on the preparation of the multimedia content and weekly questionnaires. Fortunately, we could use the videos that were recorded during the CyberAula project and the questions that the students asked for the "Materials science" in-person course. The second problem was related to the technology necessary to create multimedia resources, as the students involved in this course were very multidisciplinary and had not mastered the technology required to record a screencast. First of all, to solve this problem, we had to choose an appropriate tool to record the screencasts with the requirements of their being both free and easy to use. After a comparative study of the existing tools, the one chosen was BBFlashBack Express (2012). Combined with this we prepared a step by step manual to record a screencast. We think it is the main difficulty when applying this methodology but it can be solved 
with technical support, step by step manuals, and the teacher's help. The students also help each other a lot in the forums, so this difficulty can also have a positive aspect as it fosters collaboration.

\section{Conclusions and future work}

Currently LMSs are very advanced and available in almost every educational institution. These systems offer a variety of functionalities to carry out any didactical model that the teacher wants to apply. In this paper, we have proposed a didactical model that integrates multimedia resources with collaboration tools and peer assessment to support collaborative e-learning. This didactical model consists of five educational activities that involve both the teacher and the students. These activities will motivate students and make them aware of the power involved in learning and collaborative work, the skills they already have and can acquire, and how they can improve them.

This didactical model is the main contribution of this work. The principal difference with existing didactical models is that it is carried out with a wellknown LMS such as Moodle, together with multimedia creation tools publicly available on the Internet. The didactical model can be applied in any other scenario following its explanation and the detailed explanations of the activities presented in this paper.

This didactical model was applied to the "International Seminars on Materials Science" online course in two different semesters and scenarios with very good results. As our didactical model consist of many activities, different data can be collected from any of them to assess the efficacy, the students' participation and motivation, and finally to grade them. With these objective data and the survey conducted we can validate the initial hypothesis and confirm that the introduction of students' production of the multimedia resources together with its peer assessment encourages them to actively participate in the collaborative learning process.

The main weakness of our study is the lack of a control group, a group following the same online course but with a different didactical model, where we remove the multimedia resource creation and replace it for another kind of task such as creating a report about a topic of interest. So this will be the first and main future work. Another possibility would be to remove the peer assessment activity and replace it for traditional assessment where the teacher is the only one responsible for the evaluation.

It would also be very interesting to apply this didactical model in another scenario, for example in language courses that are so in demand in all the universities, and thus we can prove its effectiveness in other fields.

Finally, with the feedback gathered, improvements to this didactical model will be carried out. In the first place and according to the teacher feedback a very good way of improving the model would be to involve other teachers and students from former years to boost the forum activity. New activities can also be added to increase interactivity, such as videoconferencing for the students to interact 
directly with the lecturer in real time or the use of multimedia resources for remote tutor sessions.

\section{Acknowledgement}

This work is funded by the Universidad Politécnica de Madrid under the Comunica-Media project and has been developed within the framework of the Moncloa Campus de Excelencia Internacional. This project is part of the Educational Innovation Program. The authors are most grateful to the rest of the project members.

\section{References}

S. Aguirre Herrera, J. Quemada Vives, J.Y. Pastor, M.E. Martínez Izquierdo, M.Á. Mendiola Ubillos, V. Machuca and R. Portaencasa Galan, CyberAula 2.0: Integration of Moodle with Videoconferencing and Lecture Recording Services, 2011. In: World Conference on Educational Multimedia, Hypermedia and Telecommunications. pp. 291-296.

P. Anderson, What is Web 2.0? Ideas, technologies and implications for education. JISC Technology \& Standards Watch, 2007. http://www.jisc.ac.uk/media/documents/techwatch/tsw0701b.pdf (accessed 16 October 2013).

A. Bandura, Social Learning Theory, Pearson, Prentice-Hall Englewood Cliffs, NJ, 1976.

E.F. Barkley, K.P. Cross and C.H. Major, Collaborative Learning Techniques: A Handbook for College Faculty, Jossey-Bass, wiley.com, 2004.

E. Barra, S. Aguirre and J. Quemada, "Work in progress - Exploiting videoconferencing possibilities to promote the European convergence process", in 2011 Frontiers in Education Conference (FIE). IEEE, Rapid City: SD, pp. S1G-1-S1G-2, 2011.

BBFlashBack Express, 2012. Available online at: http://www.bbsoftware.co.uk/BBFlashBack_FreePlayer.aspx (accessed 17 May 2012).

D.U. Bolliger, S. Supanakorn and C. Boggs, "Impact of podcasting on student motivation in the online learning environment", Computers \& Education, 55(2), pp. 714-722, 2010.

I. Cheng, L.V. Safont, A. Basu and R. Goebel, Multimedia in Education: Adaptive Learning and Testing, World Scientific, 2010.

C.M.K. Cheung, P.-Y. Chiu and M.K.O. Lee, "Online social networks: Why do students use Facebook?" Computers in Human Behavior, 27(4), pp. 1337-1343, 2011.

V.P. Dennen, "From message posting to learning dialogues: Factors affecting learner participation in asynchronous discussion", Distance Education, 26(1), pp. 127-148, 2005.

P. Dillenbourg, Collaborative Learning: Cognitive and Computational Approaches (Advances in Learning and Instruction) (Advances in Learning and Instruction Series), Emerald Group Publishing Limited, 1999.

N. Falchikov, Improving Assessment through Student Involvement: Practical Solutions for Aiding Learning in Higher and Further Education, Routledge, 2005.

S. Ferretti, S. Mirri, L.A. Muratori, M. Roccetti and P. Salomoni, "Cooperative multimedia management for participative learning: A case study", New Review of Hypermedia and Multimedia, 14(2), pp. 177-197, 2008.

A.S. Goodsell, Collaborative Learning: A Sourcebook for Higher Education, National Center on Postsecondary, 1994.

T.D. Green and A. Brown, Multimedia Projects in the Classroom: A Guide to Development and Evaluation, Corwin Press, 2002.

C.S. Harris and D.W. Rausch, Learning Management Systems and Instructional Design, IGI Global, 2013.

J. Herrington, T.C. Reeves and R. Oliver, A Guide to Authentic e-Learning (Connecting with E-learning), Abingdon: Routledge, 2009.

$\mathrm{X}$. Jiao and C. Chen, "Thoughts on application of multimedia in education", in International Conference on Future Computer Science and Education, Xián, China, August 20-21, 2011, pp. 591-594, 2011.

A. Kendle and M. Northcote, "The struggle for balance in the use of quantitative and qualitative online assessment tasks", in 17th Annual Conference of the Australian Society for Computers in Learning in Tertiary Education (ASCILITE), Coffs Harbour, NSW, 2000.

T.D. Koschmann, Cscl: Theory and Practice of an Emerging Paradigm (Computers, Cognition, and Work), Routledge, 1996.

G. Krippel, A.J. McKee and J. Moody, "Multimedia use in higher education: Promises and pitfalls", Journal of Instructional Pedagogies, 3(2), pp. 1-8, 2010. 
N. Lambropoulos, X. Faulkner and F. Culwin, "Supporting social awareness in collaborative e-learning", British Journal of Educational Technology, 43(2), pp. 295-306, 2012.

T. Lawson, C. Comber, J. Gage and A. Cullum-Hanshaw, "Images of the future for education? Videoconferencing: A literature review", Technology, Pedagogy and Education, 19(3), pp. 295-314, 2010.

R. Likert, "A Technique for the Measurement of Attitudes", Journal: Archives of Psychology, 1932.

G. Mahajan, "Multimedia in teacher education: Perceptions and uses", Journal of Education and Practice, 3(1), pp. $5-13,2012$.

N.E. Miller and J. Dollard, Social Learning and Imitation, New Haven, CT: Yale University Press, 1941.

M. Naaman, "Social multimedia: Highlighting opportunities for search and mining of multimedia data in social media applications", Multimedia Tools and Applications, 56(1), pp. 9-34, 2012.

J. Pastor and J. Atienza, "Materials engineering degree in the Technical University of Madrid (UPM): The challenges of a new methodology", in Research in Engineering Education Symposium, Cambridge, Curran Associates Inc., 2011.

D. Pichee, 2012. Social learning: Today's workplace reality. Available online at: http://www.bizlibrary.com/ resources/white-papers/white-paper-social-learning-new-reality.aspx (accessed 17 May 2012).

B. Sbihi and K.E. El Kadiri, "Towards a participatory E-learning 2.0 A new E-learning focused on learners and validation of the content", International Journal on Computer Science and Engineering, 2(1), pp. 1-7, 2010. arXiv preprint arXiv: 1001.4738 .

M. Segers, F. Dochy and E. Cascallar, "The era of assessment engineering: Changing perspectives on teaching and learning and the role of new modes of assessment", in Optimising New Modes of Assessment: In Search of Qualities and Standards. Dordrecht: Springer, pp. 1-12, 2003.

S. Srivastava, "A study of multimedia and its impact on students' attitude", in 2012 IEEE International Conference on Technology Enhanced Education (ICTEE), Kerala, January 3-5, 2012, IEEE, pp. 1-5, 2012.

G. Stahl, T. Koschmann and D. Suthers, 2006. Computer-supported collaborative learning: An historical perspective. Available online at: http://www.cis.drexel.edu/faculty/gerry/cscl/CSCL_English.pdf (in English) http://www.cis.drexel.edu/faculty/gerry/cscl/CSCL_Chinese.pdf (in Chinese) (accessed 17 May 2012).

P.-C. Sun and H.K. Cheng, "The design of instructional multimedia in e-Learning: A media richness theorybased approach", Computers \& Education, 49(3), pp. 662-676, 2007.

B.S.P. Teoh and T.-K. Neo, "Innovative teaching: Using multimedia to engage students in interactive learning in higher education", in 2006 7th International Conference on Information Technology Based Higher Education and Training, Sydney, NSW, July 10-13, 2006, IEEE, pp. 329-337, 2006.

$\mathrm{K}$. Topping, "Peer assessment between students in colleges and universities", Review of Educational Research, 68(3), pp. 249-276, 1998.

G. Torrisi, "Collaborative learning strategies in a blended international context", Journal of e-Learning and Knowledge Society, 6(3), 71-81, 2010.

C. Ullrich, K. Borau, H. Luo, X. Tan, L. Shen and R. Shen, "Why Web 2.0 is good for learning and for research", in Proceedings of the 17th International Conference on World Wide Web - WWW'08, Beijing, China, New York: ACM Press, p. 705, 2008.

Universidad Politécnica de Madrid, 2010. ADA-Madrid report. Available online at: http://moodle.upm.es/ adamadrid/file.php/1/fichas_ada/faqs/informes/Informe_de_ADA_2010-11.pdf (accessed 7 May 2012).

UPM Educational Innovation Program, INFORME CUANTITATIVO Ocho años de Proyectos de Innovación Educativa en la UPM [Quantitative report Eight years of research projects at UPM], Madrid: UPM, 2013.

K. Zdravkova, M. Ivanović and Z. Putnik, "Experience of integrating web 2.0 technologies", Educational Technology Research and Development, 60(2), pp. 361-381, 2011. 